Canadian Journal of Higher Education Revue canadienne d'enseignement supérieur

Volume 43, No. 3, 2013, pages 78 - 91

\title{
The VIRI (Virtual, Interactive, Real-Time, Instructor-Led) Classroom: The Impact of Blended Synchronous Online Courses on Student Performance, Engagement, and Satisfaction
}

Anthony Francescucci \& Mary Foster

Ryerson University

\begin{abstract}
Previous research on blended course offerings focuses on the addition of asynchronous online content to an existing course. While some explore synchronous communication, few control for differences between treatment groups. This study investigates the impact of teaching a blended course, using a virtual, interactive, real-time, instructor-led (VIRI) classroom, on student engagement, performance, and satisfaction. We use an experimental design with both a control group and a treatment group. Up to 90 students in a large urban university are randomly assigned by the registrar into two sections of an introductory marketing course. Using a pre- and post-semester questionnaire, the study measures student engagement, performance, and satisfaction. There are no statistical differences in student performance between the control and treatment groups. The only student engagement factor with a statistically significant difference between groups is student interest in their courses. Compared with the control group, the treatment group appears to be more inter-
\end{abstract}


ested $(+10 \%)$ in their courses at the end of the semester. Finally, fewer than 2 in 10 students express dissatisfaction with their participation in a VIRI course. Blended course offerings are increasing in importance in marketing and business education. The study provides guidance for fine-tuning the features of those course offerings by demonstrating how a VIRI classroom leverages the capabilities of technology without compromising learning outcomes.

\section{Résumé}

Des recherches antérieures portant sur l'offre de cours mixtes ciblent l'ajout de contenu en ligne asynchrone à un cours préexistant. Alors que certains explorent la communication synchrone, d'aucuns effectuent un contrôle des différences entre les groupes de traitement. Cette étude examine l'impact de l'enseignement d'un cours mixte, sur l'engagement, la performance, et la satisfaction des étudiants, en utilisant une classe Virtuelle, Interactive, en temps réel (Real Time), dirigé par un Instructeur ou une Instructrice (VIRI). Nous utilisons un modèle expérimental avec un groupe, à la fois, de contrôle et de traitement. Un nombre d'étudiants qui peu atteindre 90, dans une grande université urbaine, sont aléatoirement répartis par le registraire en deux sections d'un cours introductoire de marketing. L'étude mesure l'engagement, la performance, et la satisfaction des étudiants en utilisant un questionnaire pré- et post-semestriel. Il n'existe pas de différences statistiques de performance des étudiants entre le groupe de contrôle et celui de traitement. Le seul facteur d'engagement des étudiants ayant une différence statistiquement significative entre les groupes est l'intérêt des étudiants à leurs cours. Comparé aux étudiants du groupe de contrôle, ceux et celles du groupe de traitement semble être plus intéressés $(+10 \%)$ à leurs cours à la fin du semestre. En définitive, moins que 2 étudiants sur 10 éprouvent une insatisfaction à l'égard de leur participation à un cours VIRI. Les cours mixtes gagnent en importance, notamment dans les domaines de l'éducation du marketing et des affaires. L'étude fournit des directives pour affiner les caractéristiques de ces offres de cours en démontrant comment une classe VIRI optimise les capacités de la technologie sans compromettre les résultats d'apprentissage.

In the 21st century, education is valued by participants who use education as a socioeconomic stepping stone, by employers who need skilled workers, and by governments that want to support economic productivity. In the Canadian context, for example, postsecondary attainment in the province of Ontario is currently at 59\%. However, in order to meet the requirements for knowledge workers and to increase the province's global competitiveness, the government has made a commitment to raise attainment levels to 70\% (Norrie \& Lin, 2009). Given this commitment and general provincial population increase, the Council of Ontario Universities (2010) predicts a $2 \%$ growth on average per year in university enrolment to 2020. What this number does not communicate is the uneven distribution of population growth, with the bulk occurring in the Greater Toronto 
Area (GTA). Government agencies predict a disproportionate growth in the GTA for university spots $(35,000)$ and college spots $(13,000)$ by 2015 . Estimates have gone as high as 110,000 new spots required by 2030 (Courtyard Group, 2009). At the same time as demand is increasing, Canadian government funding to support capital and other investment in post-secondary education is not keeping pace. This means many Canadian universities are feeling the urgency to explore strategies to educate more students in existing spaces without sacrificing quality. As a result, educators in the marketing area have been investigating the feasibility of offering more exclusively online or blended format courses. As widespread interest in the use of blended formats is relatively new, and the tools available are shifting because of advances in technology, it is important for instructors in marketing to understand the impact of various features of this content delivery format on student engagement, performance, and satisfaction outcomes.

Online courses and blended courses (combining online and face-to-face) have been used for more than a decade in post-secondary institutions. Introducing an online component into course delivery benefits both the university, because of reduced costs, and the learner, through greater flexibility and convenience (Sadaghiani, 2011). Developments in technological capabilities mean online course components can now include more synchronous communication to more closely mimic the experience of face-to-face classroom interaction. Previously, asynchronicity has been the norm for content delivery in online courses, combined with some synchronous tools such as instant messaging for feedback on questions (Sparks \& Mentz, 2006). The purpose of this paper is to investigate the impact of replacing traditional face-to-face lectures with virtual, interactive, real-time, instructor-led (VIRI) lectures in an existing blended course.

\section{Review of Literature}

The modalities for course delivery are changing and expanding so rapidly that the definition of what is blended is not generally applicable across research studies. Blended courses integrate the traditional face-to-face classroom experience with online elements in a way that enhances learning and is pedagogically sound. For a course to be considered blended, the portion of content delivered online or electronically must be less than $80 \%$ but more than 20\% (Garrison \& Kanuka, 2004; Klein, Noe, \& Wang, 2006).

Blended courses have various features, which makes it difficult to compare outcomes, even within the same subject area. For example, when we examine research conducted on the impact of blended learning in accounting courses, some courses use the face-toface time for traditional lectures (Keller, Hassell, Webber, \& Johnson, 2009) and report no significant differences in student outcomes when compared with the traditional model. Others have online lectures and use the face-to-face time for interactive discussion (Dowling, Godfrey, \& Giles, 2003) and report significantly positive outcomes in student achievement. Still others use the face-to-face time for a combination of lecture and discussion (Du, 2011) and report significant performance improvement, but only as a result of the in-class in-depth activities.

Means, Yoyama, Murphy, Bakia, and Jones (2009), in a comprehensive review and meta-analysis of online learning studies in the context of North America, found that on average students perform better when part or all of their learning occurs in an online 
environment compared with students who are in traditional face-to-face conditions. The authors note that this effect cannot be attributed to the delivery mechanism per se because of the difficulty controlling for differences in content, pedagogy, and learning time. Other North American studies identify the impact of certain factors - such as what is emphasized in online versus face-to-face content and the nature of instructor engagement with students - as factors that may indeed impact performance but cannot be reliably controlled (Emerson \& MacKay, 2011).

One of the main reasons why distance education programs use online course offerings is to provide access to learning for students who, because of geographic location or lifestyle, do not attend face-to-face classes. Typical course designs are built using learning management systems, such as Blackboard, and include asynchronous features such as content storage and retrieval, email communication, document drop boxes, grade inquiries, discussion boards, learning objects, and online testing. In addition, some offer synchronous chat or instant messaging (Harvey \& Lee, 2001). Much research focuses on the positive impact of online interaction on learning outcomes (Bolliger \& Martindale, 2004; Kelly, 2004), especially when it involves interaction between instructor and students (Jiang \& Ting, 2000). As a result, students value synchronous tools because questions are answered immediately and feedback is instantaneous (Park \& Bonk, 2007; Sparks \& Mentz, 2006).

In their study, Cao, Griffin, and Bai (2009) test the importance of synchronous communication among undergraduates who attend traditional face-to-face classes and find that effective synchronous communication leads directly to increased satisfaction with the course. They surmise that, although the issue of synchronous versus asynchronous has mostly been a topic related to distance education, it has relevance for traditional course settings. Current undergraduates expect to be able to communicate in a variety of ways, including online synchronous tools. The research conducted to date on these technology tools views them as separate from content delivery, whereas in a traditional classroom setting, students ask questions and receive feedback during a lecture.

Part of the review by Means et al. (2009) is to identify the practices that are associated with more effective online learning in the United States. For example, in reviewing pedagogical practices, they find that instructor-directed and collaborative/interactive learning results in significantly better outcomes than does independent/active learning. Another element reviewed is whether communication is synchronous or asynchronous. An analysis of studies that include this feature reports no significant differences in outcome. Means and her group then investigate particular features of synchronous and asynchronous online communication - including one-way video and the addition of elements such as enhanced text, graphics, coloured learning objects, and navigation options - and find no significant differences. They suggest that this is consistent with other work that positions media as a carrier of content rather than as a component that has a significant learning impact (Clark, 1994). However, Zhang, Zhou, Briggs, and Nunamaker (2006) explore the use of video by testing the impact of four different conditions: online interactive video, online noninteractive video, online nonvideo, and traditional face-to-face. While there is no significant difference between nonvideo and noninteractive video and face-toface, students with the interactive video perform significantly better than the other three groups. Further on the theme of interaction, Means et al. (2009) find that certain on- 
line features including online quizzes are not shown to be effective, whereas simulations, platforms that individualize instructions in response to learners' answers, and tools that motivate learners' reflection have positive outcomes.

The purpose of this study is to add to the body of knowledge about the impact of online synchronous communication in blended courses by (a) controlling structural features including content, assessments, and teacher for both the regular and blended format sections, which can compromise analysis and affect outcomes, and (b) including some features, such as instructor-led learning, which Means et al. (2009) identify as leading to better performance outcomes.

\section{The VIRI Classroom}

The VIRI classroom experience provides a virtual, interactive, real-time, instructorled (VIRI) teaching and learning opportunity for students. For the purpose of this research, the VIRI class is defined as a teaching and learning experience that is led by an instructor, that takes place in the online space (over the internet), where all students participate in the experience at the same time, and where the experience involves two-way communication between student and student or student and instructor. Several vendors provide VIRI-like technology. In this research, we use Cisco Systems' WebEx Training Center. Students can choose to log in to the VIRI classroom from any location including home, work, or campus. Once students log in using a personal computer and a headset, they are in the virtual classroom. The VIRI classroom contains a presentation window that is used to display course content, a video window to display a video of the speaker, and a number of tool panels (see Figure 1). The tool panels include a participant list window to display the names of students attending the VIRI classroom, a chat tool to allow class participants to engage in public or private chats with one another, a question and answer tool to allow class participants to ask public questions to the instructor, and a polling tool to allow the instructor to poll class participants in real time to solicit feedback on specific topics. The participant window also provides a number of indicators and tools to help the instructor manage VIRI classroom interaction. The participant window indicates who is online, who has a working headset installed, and who has a microphone engaged; it also displays an individual feedback icon for each student. Students can use their feedback icon to provide nonverbal feedback to the instructor such as, "I'm confused," "Slow down the pace," "Increase the pace," or "I'd like to ask a question." The VIRI classroom environment allows the instructor to engage with the students almost as they would in a face-to-face classroom. For example, the instructor can lecture on a topic and then engage students by asking a question and asking for a student to respond verbally. The instructor can also break the students into groups for small group discussion and then bring them back to the large group to debrief on the topic. The VIRI classroom allows the session to be recorded to help maintain a record of attendance; and, if desired, the recording can be made available to students for review or to those who missed the session. 


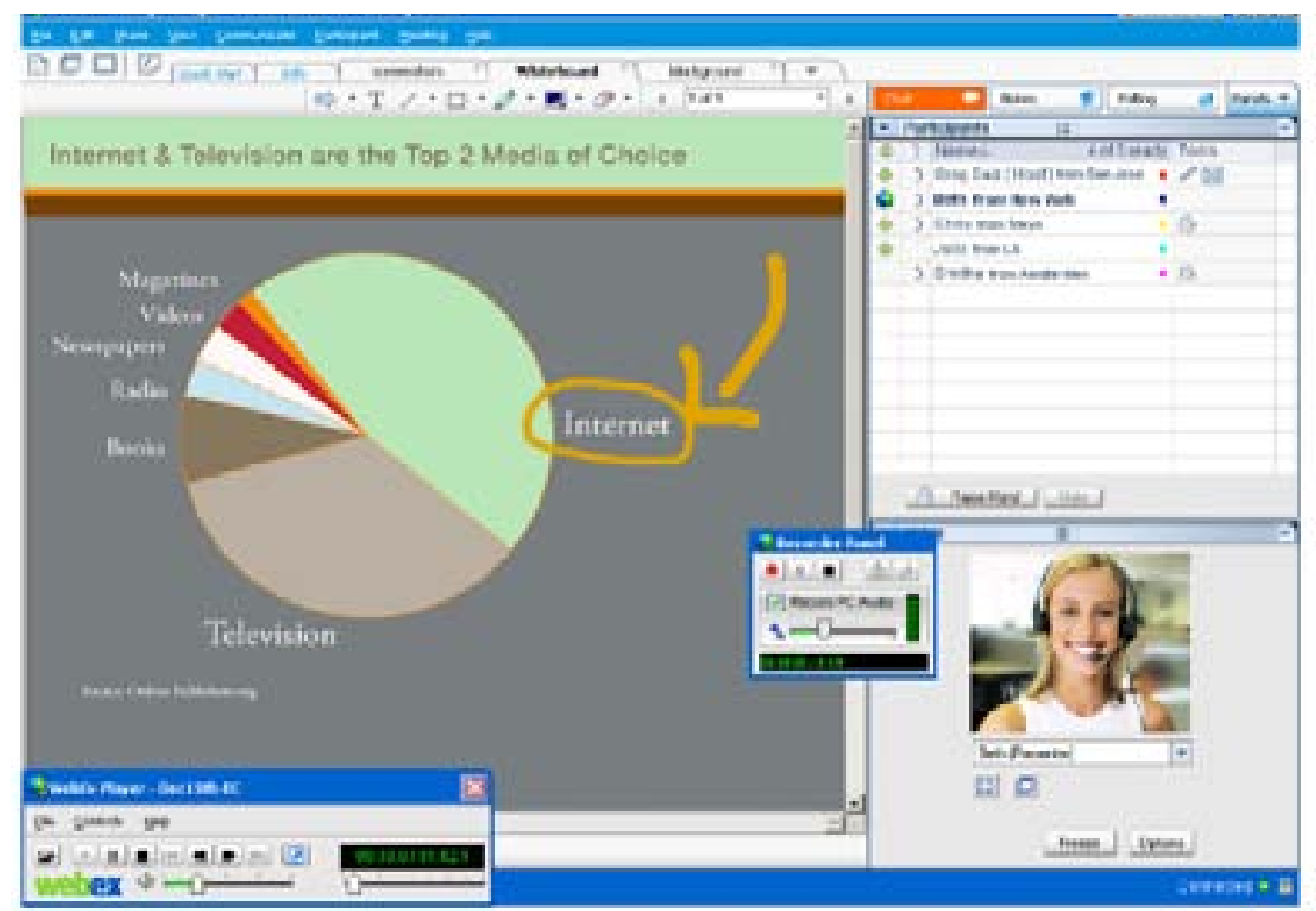

Source: WebEx Press Kit, retrieved from http://www.webex.com.hk/en/webex/press-kit.html

Figure 1. Image of VIRI technology

\section{Research Questions}

The main focus of this study is to explore the impact, if any, on learning outcomes of using virtual, interactive, real-time, instructor-led (VIRI) classes supported by webbased technology that replaces half of the traditional face-to-face classroom teaching. The research examines the effect, if any, of this VIRI technology on student performance, engagement, and satisfaction as a result of shifting courses from solely traditional faceto-face learning to a mix of face-to-face and synchronous online learning. Specifically, the study seeks to answer the following questions:

1. Compared with students taking traditional face-to-face classes, how do students in a blended VIRI class perform on standard course assessments?

2. Compared with students taking traditional face-to-face classes, how do students in a VIRI class perceive their engagement levels?

3. After participating in a VIRI class, how satisfied are participants with their experience and what is their attitude toward participating in VIRI classes?

\section{Method}

This study compares two sections of an introductory marketing course at a large urban university. The analysis employs an experimental design, which includes both a control group section and a treatment group section. As is done with all multi-section courses at this university, the registrar randomly assigns students to different sections (maximum 90 students in each section) of an introductory marketing course. Two different sections taught by the same instructor in the same semester are used for the control and treatment groups. 
Students in both groups are asked to complete pre- and post-semester questionnaires that contain questions measuring student engagement and performance factors. The students in the treatment group also respond to questions about their experience in the VIRI classroom, including satisfaction and propensity to take another VIRI class. Students are offered one bonus mark for each pre- and post-semester survey completion as an incentive. The sample size consists of 44 students in the control group and 36 students in the treatment group.

To minimize the variance caused by course format factors, the same instructor teaches both sections in the same semester, and at the same time of day. Both groups receive the same lectures, assignments, mid-term tests, and final examinations (all tests and examinations for both groups are conducted in the face-to-face classes). Similarly, both groups have access to all the same online course resources available through Blackboard (such as announcements, email, practice tests, quizzes, instructor slides, assignment instructions, and evaluation rubrics). The only difference between the two groups is the method of lesson delivery. The control group meets in a traditional face-to-face classroom during all weeks of the course, and the treatment group meets in both the face-to-face classroom and the VIRI classroom. Beginning in the second week of a 13-week semester, the treatment group alternates between attending face-to-face classes and participating in the VIRI classroom. Students in the treatment group attend class at the same time and day of the week; but on alternate weeks, instead of coming to the classroom, they log in using their computer and headset from a remote location.

We derive the items chosen to measure the six student engagement indicators from the standard measures used in the National Survey on Student Engagement (NSSE). NSSE is a North American study, conducted by the NSSE Institute, in which many universities throughout the United States and Canada participate; many schools use the results to assess student engagement on their own campuses. Student engagement in this study includes the student's perception of their engagement on the following items: attending class, participating in class, interest in courses, paying attention in class, staying up to date on academic workload, and instructor interaction outside the class.

For the purposes of analysis, we include only those students who participate in both the pre- and post-semester surveys. We use analysis of variance (ANOVA) to compare the differences between groups for the student engagement and performance factors. We compare the differences in engagement factors between the groups at the start and at the end of the semester. We also investigate the change in individual engagement scores, by calculating the difference between the scores at the beginning of the semester and those at the end of the semester for each individual student. Finally, we compare the mean of the individual differences in engagement scores for both groups between the beginning and the end of the semester. Given that we ask only the treatment group about their satisfaction with the blended course, we present these results as means.

\section{Findings}

\section{Student Performance}

The first research question focuses on the performance outcomes of the control and treatment groups. We use the means for each of the major individual assessments (mid- 
term test, $30 \%$, and final examination, $40 \%$ ) in the introductory marketing course to identify differences, if any, in student performance. We choose these assessments because they are standardized for the two groups, and we conduct them in a controlled setting to ensure the integrity of the assessment. As Table 1 indicates, there are no statistically significant differences between the means for these assessments for the two groups. Anecdotally, these performance outcome means are consistent with those of the other 14 traditional face-to-face sections of introductory marketing, which are taught by seven other instructors and which use the same mid-term test and final examination.

Table 1

ANOVA of Student Performance Outcomes

\begin{tabular}{lccc}
\hline Performance outcome & $\begin{array}{c}\text { Control group } \\
\text { mean (\%) }\end{array}$ & $\begin{array}{c}\text { Treatment group } \\
\text { mean (\%) }\end{array}$ & Significance \\
\hline Mid-term test grade & 69 & 70 & 0.599 \\
Final examination grade & 65 & 63 & 0.295 \\
\hline
\end{tabular}

\section{Student Engagement}

The second research question focuses on the impact of a blended learning delivery on student engagement. Table 2 provides the ANOVA results for the six engagement indicators. When students are polled at the beginning of the semester, there are no statistically significant differences between students in the control group or the treatment group in their expectations regarding attending class, interest in their current courses, their ability to stay on top of their academic workload (such as staying up to date with readings and assigned work), and interacting with the instructor outside of the classroom. In the pre-semester survey, results indicate that students in the treatment group have significantly higher expectations regarding participating in class and being able to pay attention during class.

At the end of the semester, when we ask students about their actual engagement during the course of the semester, the factors with a statistically significant difference include participating in class, interest in the course they took during the semester, and being able to pay attention during class. The results indicate that the treatment group reports having better participation, interest, and attention scores compared with the control group. There are no other statistically significant differences between the two groups.

Given that the differences between the two groups on participating in class and being able to pay attention during class persist from the pre-semester survey to the postsemester one, it is important to determine whether the differences are amplified after the blended learning experience. The pre- and post-semester delta column in Table 2 compares individual differences. It indicates that there are no statistically significant differences in the variances between the engagement scores at the beginning and at the end of the semester, suggesting that the level of engagement among students in the treatment and control groups changes at a similar rate during the 13-week course. The higher levels of engagement in the treatment group identified in the pre-semester survey are maintained rather than amplified by the blended learning experience. 


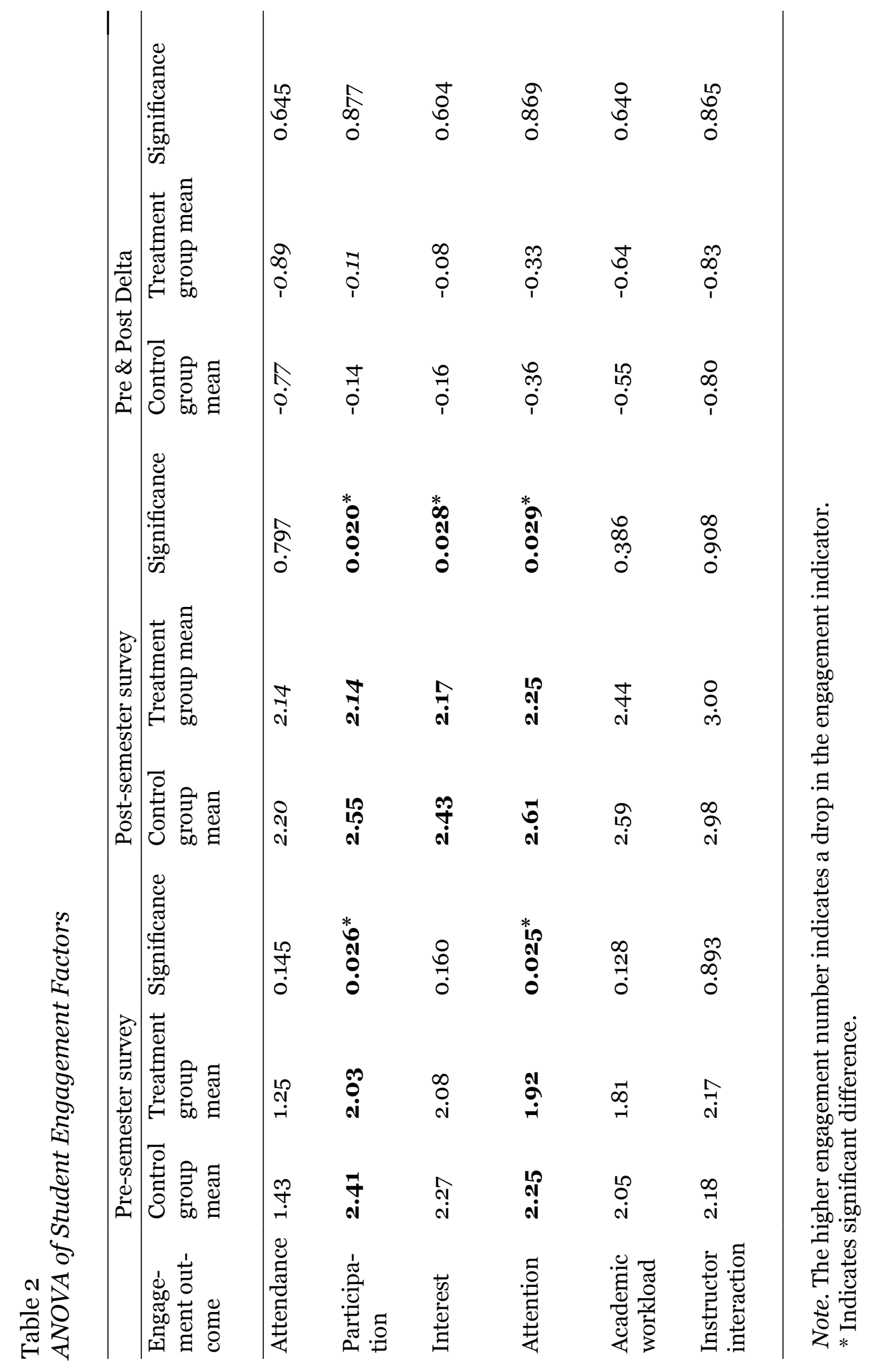




\section{Student Satisfaction}

We ask participants in the treatment group questions related to their overall satisfaction as well as satisfaction with individual aspects of the blended course. Table 3 provides a summary of those results. Of particular note is the degree of overall satisfaction with the VIRI version of the introductory marketing course. Fewer than two out of 10 report dissatisfaction with the VIRI course. Further, fewer than two out of 10 report never wanting to take a VIRI course again.

Table 3

Satisfaction Indicators for Treatment Group

\begin{tabular}{|c|c|c|c|c|}
\hline & Mean & $\begin{array}{l}\text { Agree* }^{*} \\
\%\end{array}$ & $\underset{\%}{\underset{\%}{\text { Disagree }}{ }^{* *}}$ & $\begin{array}{l}\text { Neutral } \\
\%\end{array}$ \\
\hline $\begin{array}{l}\text { Your OVERALL satisfaction with the MKT10o VIRI } \\
\text { course you took this semester. }\end{array}$ & 3.5 & 58 & 15 & 27 \\
\hline $\begin{array}{l}\text { I enjoyed the virtual lectures as much as the face-to- } \\
\text { face lectures. }\end{array}$ & 3.2 & 43 & 35 & 22 \\
\hline $\begin{array}{l}\text { I prefer this VIRI course over the other face-to-face } \\
\text { courses that I took this semester. }\end{array}$ & $3 \cdot 3$ & 47 & 31 & 22 \\
\hline $\begin{array}{l}\text { I would never take a VIRI or virtual lecture course } \\
\text { again. }\end{array}$ & 2.2 & 18 & 61 & 20 \\
\hline $\begin{array}{l}\text { I wish more of my courses used a VIRI course delivery } \\
\text { method. }\end{array}$ & 3.2 & 47 & 33 & 20 \\
\hline $\begin{array}{l}\text { I would consider taking a course which is completely } \\
\text { virtual with no face-to-face classes. }\end{array}$ & 3.1 & 39 & 37 & 24 \\
\hline $\begin{array}{l}\text { I found it easy to connect / login to the online virtual } \\
\text { lectures. }\end{array}$ & 4.2 & 80 & 8 & 12 \\
\hline $\begin{array}{l}\text { I would rather just come to a regular class then deal } \\
\text { with getting online. }\end{array}$ & 2.9 & 38 & 44 & 19 \\
\hline $\begin{array}{l}\text { I found it difficult to keep track of when classes were } \\
\text { online versus in-class. }\end{array}$ & 1.9 & 16 & 78 & 6 \\
\hline $\begin{array}{l}\text { It was a challenge for me to connect to the virtual lec- } \\
\text { ture each time. }\end{array}$ & 1.7 & 8 & 79 & 13 \\
\hline $\begin{array}{l}\text { Attending the virtual lectures was just as convenient as } \\
\text { coming to class. }\end{array}$ & 3.1 & 37 & 35 & 29 \\
\hline $\begin{array}{l}\text { Attending the virtual lectures was more convenient } \\
\text { than coming to class. }\end{array}$ & 3.6 & 54 & 27 & 19 \\
\hline $\begin{array}{l}\text { Attending the virtual lectures was more stressful than } \\
\text { coming to the face-to-face classes. }\end{array}$ & 2.5 & 22 & 49 & 29 \\
\hline $\begin{array}{l}\text { I found it more comfortable to speak during the virtual } \\
\text { lectures than during the face-to-face lectures. }\end{array}$ & 2.8 & 33 & 43 & 24 \\
\hline $\begin{array}{l}\text { It was easier to ask a question or say something during } \\
\text { the face-to-face lectures versus the virtual lectures. }\end{array}$ & $3 \cdot 3$ & 40 & 23 & 38 \\
\hline
\end{tabular}

*Includes strongly and somewhat agree.

${ }^{* *}$ Includes strongly and somewhat disagree. 
A significant majority of the students report finding it easy to connect or log in to the VIRI classroom (80\%) and keep track of when classes are online (78\%). More than half of respondents (54\%) report finding it more convenient to attend class in the VIRI classroom than to come to a face-to-face classroom. Fewer than a quarter of students (22\%) report finding it more stressful to attend a VIRI class rather than a traditional class.

\section{Discussion}

We conducted this research to add to the body of knowledge about the impact of the features of online blended courses on learning outcomes, by focusing on the effect of a virtual, interactive, real-time, instructor-led (VIRI) environment on performance. The main focus of most previous research has been on asynchronous online learning, with synchronous tools being limited to feedback on questions through online chat, or to simultaneous transmission of lectures on a video screen with no opportunity for interaction. This study adds to this body of knowledge because it tests the impact of synchronous tools that mimic the classroom experience. Students can answer questions, ask questions, and debate with each other in real time online.

The first research question compares performance outcomes between the control and treatment groups. The results suggest that alternating between a VIRI and a traditional face-to-face classroom has no impact on assessment outcomes in an introductory marketing class. This is an important finding because it means that universities can handle increased student numbers in existing space without compromising their commitment to quality teaching. At the current time, when funds for post-secondary education are in the best case remaining stable and in the worst case decreasing, these results suggest that significant capital investment in physical classroom space is not the only solution to handling increasing post-secondary participation rates.

Further, the results suggest that transitioning students to a VIRI classroom for half of their classes has minimal impact on student engagement. This is an important finding because of the documented relationship between engagement and performance (Carini, Kuh, \& Klein, 2006; Kuh, Cruce, Shoup, Kinzie, \& Gonyea, 2008; Salanova, Schaufeli, Martinez, \& Breso, 2010). Engagement is of particular concern for courses with an online component, because of the impact of readily available online resources on class attendance and subsequent performance (Grabe, Christopherson, \& Douglas, 2005; Weatherley, Grabe, \& Arthur, 2003). Results have been mixed, with some studies finding lowered performance associated with online resource availability (Weatherley et al., 2003), while others find that performance is positively related to how often online resources are accessed (Grabe \& Christopherson, 2005). Stewart, Stott, and Nuttall's (2011) study the use student engagement patterns and their influence on attendance, performance, and use of online resources finds that when online resources are mostly used as a content repository, students do not engage with the material regularly or interactively, but rather they use it in a fashion similar to how they access resources at the library. Their results underline the effectiveness of blended learning approaches, and also the need for more interactive tools to engage students. Given that the VIRI classroom has no impact on student attendance, ability to keep up with academic workload, or interaction with the instructor outside the classroom, it suggests the virtual, interactive, real-time, and instructor-led features may 
be the format that addresses some of the shortcomings identified in current online offerings by Stewart and his colleagues (2011). Further, this format may even have the capacity to increase engagement by combining the best of the learning features of online and faceto-face as indicated by the modest positive differences reported by the treatment group for student participation in class, interest in their courses, and attention in class.

Despite these positive results, student satisfaction with VIRI courses appears to be mixed. While eight in every 10 students are satisfied overall or neutral about the VIRI course and also favourable or neutral toward taking another VIRI course again, over onethird of participants have dissenting feelings about the VIRI course. For example, they disagree with statements that VIRI lectures are as enjoyable as face-to-face and are as preferable as face-to-face. Likewise, a similar proportion do not want more VIRI courses, nor will they consider taking a course that is entirely in a VIRI classroom. The root cause of these concerns is not clear, as the majority of students report no technical difficulties and the engagement levels are similar to those in the control group. It may be that this is such a new way of learning that students are not comfortable with how to respond and participate at the level required to benefit from the features of the VIRI classroom. The implication is that additional work needs to be done to understand the barriers and facilitators to engagement in the VIRI environment.

Overall, this study suggests that if the post-secondary education sector migrates to increased usage of VIRI technology to deliver some lectures, the impact on student engagement, performance, and satisfaction will be minimal.

\section{Limitations and Future Research}

We conducted this study with only one instructor, in a single discipline, and at an introductory course level. While an important contribution, it may not be generalizable to other disciplines and at more senior levels of study. Future research may consider multiple instructors, multiple disciplines, and varying levels of study. Finally, future research may also consider a treatment where all class lessons are conducted in a VIRI classroom versus a traditional face-to-face classroom.

\section{References}

Bolliger, D.U., \& Martindale, T. (2004). Key factors for determining student satisfaction in online courses. International Journal on E-Learning, 3(1), 61-67.

Cao, Q., Griffin, T. E., \& Bai, X. (2009). The importance of synchronous interaction for student satisfaction with course websites. Journal of Information Systems Education, 2O(3), 331-338.

Carini, R. M., Kuh, G. D., \& Klein, S. P. (2006). Student engagement and student learning: Testing the linkages. Research in Higher Education, 47(1), 1-32.

Clark, R. E. (1994). Media will never influence learning. Educational Technology Research and Development, 42(2), 21-29.

Council of Ontario Universities. (2010). Position paper: Framework for planning and funding of enrolment. Retrieved from www.cou.on.ca/issues-resources/key-issues/ pdfs/framework-for-planning-and-funding-of-enrolment.aspx 
Courtyard Group. (2009). MTCU/MEI long term capital planning project. Retrieved from http://www.yorku.ca/oira/reports/GreenPaper/16\%20-\%20MTCUMEILongTermCapitalPlanningProject.pdf

Dowling, C., Godfrey, J. M., \& Gyles, N. (2003). Do hybrid flexible delivery teaching methods improve accounting students' learning outcomes? Accounting Education, 12(4), 373-391.

Du, C. (2011). A comparison of traditional and blended learning in introductory principles of accounting course. American Journal of Business Education, 4(9), 1-10.

Emerson, L., \& MacKay, B. (2011). A comparison between paper-based and online learning in higher education. British Journal of Educational Technology, 42(5), 727-735.

Garrison, D.R., \& Kanuka, H. (2004). Blended learning: Uncovering its transformative potential in higher education. Internet and Higher Education, 7, 95-105.

Grabe, M., \& Christopherson, K. (2005). Evaluating the advantages and disadvantages of providing lecture notes: The role of internet technology as a delivery system and research tool. Internet and Higher Education, 8, 291-298.

Grabe, M., Christopherson, K., \& Douglas, J. (2005). Providing introductory psychology students access to online lecture notes: The relationship of note use to performance and class attendance. Journal of Educational Technology Systems, 33, 297-310.

Harvey, D. M., \& Lee, L. (2001). The impact of inherent instructional design in online courseware. Quarterly Review of Distance Education, 2(1), 35-48.

Jiang, M., \& Ting, E. (2000). A study of factors influencing students' perceived learning in a web-based course environment. International Journal of Educational Telecommunications, 6(4), 317-338.

Keller, J. H., Hassell, J. M., Webber, S. A., \& Johnson, J. N. (2009). A comparison of academic performance in traditional and hybrid sections of introductory managerial accounting. Journal of Accounting Education, 27(3), 147-154.

Kelly, H. (2004). Enhancing interpersonal interaction in online courses. Educational Technology, 44(1), 53-56.

Klein, H. J., Noe, R. A., \& Wang, C. (2006). Motivation to learn and course outcomes: The impact of delivery mode, learning goal orientation and perceived barriers and enablers. Personnel Psychology, 59(3), 665-702.

Kuh, G. D., Cruce, T. M, Shoup, R., Kinzie, J., \& Gonyea, R. M. (2008). Unmasking the effects of student engagement on first-year college grades and persistence. Journal of Higher Education, 79(5), 540-563.

Means, B., Yoyama, Y., Murphy, R., Bakia, M., \& Jones, K. (2009). Evaluation of evidence-based practices in online learning: A meta-analysis and review of online learning studies. US Department of Education. Office of Planning, Evaluation, and Policy Development. Policy and Program Studies Service.

Norrie, K., \& Lin, S. (2009). Postsecondary education attainment and participation in Ontario. Toronto: Higher Education Quality Council of Ontario. 
Park, Y .J., \& Bonk, C.J. (2007). Synchronous learning experiences: Distance and residential learners' perspectives on a blended graduate course. Journal of Interactive Online Learning, 6(3), 245-264.

Sadaghiani, H. R. (2011). Using multimedia learning modules in a hybrid-online course in electricity and magnetism. Physical Review Special Topics - Physics Education Research, 7(010102), 1-7.

Salanova, M., Schaufeli, W., Martinez, I., \& Breso, E. (2010). How obstacles and facilitators predict academic performance: The mediating role of study burnout and engagement. Anxiety, Stress \& Coping, 23(1), 53-70.

Sparks, P., \& Mentz, L. (2006). Electronic note passing: Enriching online learning with new communication tools. MERLOT Journal of Online Learning and Teaching, 2(4), 268-274.

Stewart, M., Stott, T., \& Nuttall, A. M. (2011). Student engagement patterns over the duration of level 1 and level 3 geography modules: influences on student attendance, performance and use of online resources. Journal of Geography in Higher Education, 35(01), 47-65.

Weatherly, J. N., Grabe, M., \& Arthur, E. I. (2003). Providing introductory psychology students access to lecture slides via Blackboard 5: A negative impact on performance. Journal of Educational Technology Systems, 31(4), 463-474.

Zhang, D., Zhou, L., Briggs, R. O., \& Nunamaker, J. F., Jr. (2006). Instructional video in e-learning: Assessing the impact of interactive video on learning effectiveness. Information and Management, 43(1), 15-27.

\section{Contact Information}

Anthony Francescucci

Ted Rogers School of Management

Ryerson University

a.frances@ryerson.ca

Anthony Francescucci is an assistant professor of marketing in the Ted Rogers School of Management at Ryerson University in Toronto. His research interests include topics related to B2B relationship marketing and business performance, social media, real-time virtual classrooms, hybrid classrooms and learning, and resistance to giving up existing innovations.

Mary Foster is a professor of marketing and the Ted Rogers School of Management Teaching Chair at Ryerson University. Her areas of research interest include management education, online social networks, online marketing research, and non-profit and voluntary sector studies. She has designed a "flipped" version of an introductory marketing course and is currently piloting its delivery with 150 first-year students. She has a doctorate from Columbia University 